\title{
Justicia restaurativa y Sistema Interamericano de Derechos Humanos
}

Fecha de recepción: 26 de octubre de 2018

Fecha de aceptación: 17 de agosto de 2019

Doi: https://doi.org/10.12804/revistas.urosario.edu.co/acdi/a.7359

\section{Shirley Vanessa Méndez Romero** Norberto Hernández Jiménez ${ }^{* * *}$}

Resumen: el presente documento realiza un recorrido en torno a la noción de justicia restaurativa y a las herramientas que pueden ser aplicadas a través de las soluciones amistosas, en el marco del Sistema Interamericano de Derechos Humanos. De manera primigenia se hace un recuento de los modelos punitivos existentes con el objetivo de brindar un panorama general en materia del castigo y su efectividad. Igualmente se muestra el

* Artículo de reflexión, derivado del proyecto de investigación independiente de los autores.

** Asesora docente del Centro de Conciliación de la Universidad de los Andes (Bogotá). Abogada de la Universidad Católica de Colombia (Bogotá). Especialista en derecho constitucional de la Universidad del Rosario (Bogotá). Magíster en derechos humanos de la Universidad Iberoamericana (Ciudad de México).Correo electrónico:sv.mendez@) uniandes.edu.co

*** Profesor asistente de la Facultad de Ciencias Jurídicas de la Pontificia Universidad Javeriana (Bogotá) y miembro del grupo de investigación en Justicia Social, Teoría Jurídica General y Teoría Política. Abogado, especialista y magíster en derecho penal de la Universidad Libre (Bogotá). Especialista en derecho constitucional y en derecho administrativo de la Universidad del Rosario (Bogotá). Máster en criminología y ejecución penal de la Universitat Pompeu Fabra (Barcelona). Doctor en derecho por la Universidad de los Andes (Bogotá). Correo electrónico: norbertohenandezj@javeriana.edu.co

Para citar este artículo: Méndez Romero, S. V. \& Hernández Jiménez, N. "Justicia restaurativa y Sistema Interamericano de Derechos Humanos". Anuario Colombiano de Derecho Internacional (ACDI) 13, 2020, 47-78. https://doi.org/10.12804/revistas.urosario.edu.co/acdi/a.7359 
tratamiento que tiene la víctima de un delito a nivel local, que en oportunidades alcanza un acuerdo con el victimario, situación que puede acontecer de la misma forma cuando el menoscabo de sus derechos fundamentales fue ocasionado por parte de un Estado. En este contexto, se mostrará cómo la práctica de la justicia restaurativa permite la devolución del conflicto a las partes y, con ello, la satisfacción de sus derechos de una manera expedita, más efectiva y menos técnica que la que demandan el ambiente jurídico local e interamericano.

Palabras clave: justicia restaurativa, soluciones amistosas, derechos humanos, modelos punitivos.

\section{Restorative Justice and the Interamerican System of Human Rights}

Abstract: This paper studies the frame of the restorative justice and friendly solutions applicable within the inter-American human rights system. First of all, the guidelines of punitive models are shown to provide an overview of punishment and its effectiveness. Likewise, researchers present the victim's treatment at the local context, who sometimes achieves an agreement with the offender, a situation that can happen in the same way when the violation of their fundamental rights caused by a State. In this context, it is shown how the implementation of restorative justice allows the return of the conflict to the people involved in it and with it the stronger satisfaction of their rights (fast, effective, and easy). This practice is less technical than the one required by the local and interAmerican legal systems.

Keywords: Restorative justice, friendly solutions, human rights, punitive models. Justiça restaurativa e sistema interamericano
de direitos humanos

Resumo: o presente documento realiza um recorrido no que se refere à noção de justiça restaurativa e as ferramentas que podem ser aplicadas através das soluções amistosas, no marco do sistema interamericano de 
direitos humanos. De maneira primigénia se faz uma contagem dos modelos punitivos existentes com o objetivo de brindar um panorama geral em matéria de castigo e sua efetividade. Igualmente, mostra o tratamento que tem a vítima de um delito no nível local, que em oportunidades alcança um acordo com o agressor, situação que pode acontecer da mesma forma quando o menoscabo de seus direitos fundamentais foi ocasionado por parte de um Estado. Neste contexto, se mostrará como a prática da justiça restaurativa permite a devolução do conflito às partes e com isto, a satisfação de seus direitos de uma maneira expedita, mais efetiva e menos técnica que a que demanda o ambiente jurídico local e interamericano.

Palavras-chave: justiça restaurativa, soluções amistosas, direitos humanos, modelos punitivos.

\section{Introducción}

Uno de los temas más álgidos dentro del campo del derecho en la actualidad tiene que ver con la protección de los derechos humanos y su justiciabilidad en escenarios locales e internacionales. Estos temas, lejos de ser una moda, tienen un alto grado de importancia y complejidad por ser hondamente sensibles. La vulneración de estas prerrogativas fundamentales desemboca en situaciones sumamente desfavorables para quienes las sufren, que exigen los estándares más altos de investigación, persecución y sanción para evitar así la repetición de acontecimientos que degraden la condición del ser humano en cuanto tal y su propia existencia.

Desde este entendido, pensar en solucionar una situación que quebrantó los derechos humanos de una persona en forma convenida con el autor de esta resulta para muchos un despropósito, una burla y una anulación de estas máximas fundamentales que se reconocieron en favor de la protección de la raza humana. En todo caso, debe avizorarse que las concepciones tradicionales de justicia como sinónimo de castigo y retribución del mal ocasionado vienen siendo reevaluadas ante su notorio fracaso y reemplazadas por otras diametralmente distintas en las que, más allá de la imposición de una sanción, se busca solucionar la situación que originó el conflicto, sin dejar de lado su objetivo principal: reparar el perjuicio causado a la víctima.

En ese contexto se posiciona la justicia restaurativa como un modelo que prioriza la sanación de las heridas y la devolución del conflicto a las 
partes, ${ }^{1}$ rechazando la retribución del mal causado como único mecanismo de administración de justicia. El tema — aunque parece novedoso- tiene una larga tradición en algunas comunidades, cuyos resultados en su aplicación la posicionan como una herramienta idónea para obtener justicia en determinados contextos.

\section{Horizonte metodológico}

El problema de investigación se resume en la siguiente pregunta: ¿las soluciones amistosas del Sistema Interamericano de Derechos Humanos se corresponden con los lineamientos de la justicia restaurativa?

Para resolver este problema, de manera inicial, se analizaron los diversos modelos punitivos para la administración del castigo —en general-, enfatizando el del modelo reparador/restaurador y sus diferencias con el modelo retributivo. Con esta base teórica, fruto de una revisión bibliográfica reflexiva y académicamente crítica, se estudió la aplicación de la restauración en el Sistema Interamericano de Derechos Humanos (SIDH) con base en las soluciones amistosas, ${ }^{2}$ conjugando en todos los casos la comparación de la administración de justicia en el ámbito local y global.

\section{Modelos punitivos ${ }^{3}$}

En la actualidad suelen diferenciarse cuatro modelos punitivos para la imposición del castigo: (i) proporcionalista, (ii) rehabilitador, (iii) reparador/restaurador y (iv) incapacitador/inocuizador. De estos modelos, el que privilegia la pena privativa de la libertad es el inocuizador, mientras

\footnotetext{
1 Antonio Beristain, Nueva criminología desde el derecho penal y la victimología, (Valencia: Tirant lo Blanch, 2004), 342; Christie Nils, "Conflicts as property," The British Journal of Criminology 17, no. 1 (1977).

2 Las soluciones amistosas son una herramienta mediante la cual puede resolverse de forma no contenciosa y acordada por las partes la situación o petición llevada ante la Comisión Interamericana de Derechos Humanos (CIDH), en donde el Estado, dando cumplimiento a los propósitos de la convención, busca principalmente reparar a la víctima mediante diversas formas que pueden incluir el restablecimiento del derecho — cuando este sea posible-, la rehabilitación médica, psicológica y social, medidas de satisfacción, compensación económica y medidas de no repetición.

3 Esto fue desarrollado preliminarmente en Norberto Hernández, De la privación a la restricción de la libertad y otras sanciones penales. ¿Hacia un paradigma restaurativo en la justicia especial para la paz colombiana? (Inédito).
} 
que los modelos rehabilitador y reparador se apartan de esa asociación de delito y cárcel. Por su parte, el proporcionalista deja reservada la pena de prisión para los delitos graves; tratándose de otros delitos menos graves o leves, podrán aplicarse penas alternativas dentro de las cuales pueden considerarse adecuadas las multas o el trabajo en beneficio de la comunidad. ${ }^{4}$

\subsection{Modelo proporcionalista}

Con base en la teoría de Wasik y von Hirsch (1998) se desarrolla este modelo, donde la gravedad del delito es el eje central de su aplicación. Para esto se propone una escala de castigos que asocie la gravedad de estos con la del delito: delito grave-castigo grave, delito leve-castigo leve. ${ }^{5}$

Se advierte nuevamente que no es la prisión la única alternativa para reprimir el comportamiento del delincuente. Con base en criterios de proporcionalidad podrían imponerse penas pecuniarias o alternativas a esta como el trabajo en beneficio de la comunidad, fuertemente implementado en España e inspirado en el mandato constitucional (artículo 25-2) de reeducación y reinserción social respecto de las penas, que adquiere igualmente gran importancia en el desarrollo del modelo rehabilitador.

\subsection{Modelo rehabilitador}

Este modelo excluye la prisión como primera opción; ${ }^{6}$ privilegia la resocialización del individuo, lo cual ocurre de mejor manera en libertad, ${ }^{7}$

\footnotetext{
4 Algunos estudios muestran que, en contextos como el español, la sociedad no se opone al uso de esta clase de medidas y, por el contrario, tienden a patrocinarlas. Cfr. Daniel Varona, "¿Somos los españoles punitivos? Actitudes punitivas y reforma penal en España", Revista Indret 1, (2009); Daniel Varona, "Ciudadanos y actitudes punitivas: Un estudio piloto de población universitaria española", Revista Española de Investigación Criminológica 6, (2008), 1-38. En el mismo sentido, el estudio replicado en Medellín. Cfr. Juan Uribe, "Actitudes de los ciudadanos frente al crimen y al castigo: estudio piloto en la Universidad EAFIT, Medellín”, Revista Nuevo Foro Penal 9, no. 81 (2013).

5 Jose Cid, La elección del castigo, (Barcelona: Bosch, 2009), 29.

6 Francis Cullen y Karen Gilbert, Reaffirming Rebabilition, (Cincinnati: Anderson Publishing, 1981).

7 Al respecto es importante traer a colación el símil que hace Zaffaroni — citado por Elías Carranza, "Situación penitenciaria en América Latina y el Caribe ¿Qué hacer?",
} 
dejando aquella reservada a la imposibilidad de realizar el tratamiento rehabilitador sin el internamiento. Así, busca que el individuo no vuelva a delinquir en el futuro, atacando los factores específicos que lo vinculan con la comisión de delitos. ${ }^{8}$

En este punto es importante señalar que el trabajo es un instrumento esencial para obtener el fin de la resocialización ${ }^{9}$ no solo por su potencialidad moralizadora, ${ }^{10}$ sino por la posibilidad implícita que, a través del conocimiento de un oficio intramuros, este se puede realizar en libertad, procurando la subsistencia del condenado y la evitación de delitos como consecuencia directa. Pero no toda clase de trabajo es adecuada para la consecución de este fin. Por ejemplo, las colonias agrícolas son atractivas frente a la arquitectura carcelaria obsoleta, cuyas murallas representan la imposibilidad de contacto con el mundo exterior, cuando la vida de campo y el trabajo agrícolas son útiles para aquellas personas cuyo entorno futuro puede beneficiarse de esta labor. No ocurre lo mismo con aquellos que habitan las urbes en la actualidad, cuyo conocimiento de este trabajo se tornará poco fecundo ${ }^{11}$ para las labores que demanda la sociedad industrializada.

\subsection{Modelo reparador/restaurador}

Tomando como referente la obra de Braithwaite, ${ }^{12}$ el modelo reparador o restaurador se enfoca en la víctima. Pretende la reparación del daño y la paz social. Para lograr estos objetivos, las partes afectadas con el conflicto se ponen en contacto y solucionan la controversia; la prisión queda reservada a los eventos en que la justicia reparadora no logre sus objetivos. ${ }^{13}$

Anuario de Derechos Humanos, (2012), 46 - sobre la imposibilidad de socializar la vida en libertad dentro de la prisión y pretender enseñar a nadar en una piscina sin agua.

8 Cid, La elección del castigo, 30.

9 Michel Foucault, Vigilar y castigar. Nacimiento de la prisión, (Buenos Aires: Siglo XXI Editores, 1976), 275.

10 Francisco Lastres, Estudios Penitenciarios, (Madrid: Jiménez Gil Editor, 1887), 71.

11 Ibíd.

12 John Braithwaite, Restorative justice and responsive regulation, (Nueva York: Oxford University Press, 2002).

13 Cid, La elección del castigo, 30. 
Este modelo consagra como uno de sus instrumentos la vergüenza reintegrativa, ${ }^{14}$ que se acerca a la infamia pregonada por Foucault, ${ }^{15}$ que utiliza la opinión pública para castigar los delitos, sin acudir al uso universal de la prisión. La justicia restaurativa se encuadra dentro de este modelo.

\subsection{Modelo inocuizador}

El objetivo de este modelo es neutralizar al delincuente e impedir que delinca durante el tiempo que se encuentre privado de la libertad. ${ }^{16}$ Teniendo en cuenta la distribución de los escasos recursos, este modelo no utiliza la prisión de manera generalizada, sino que la deja reservada para las personas que presenten mayor riesgo de reincidencia en el delito. ${ }^{17}$

Con base en esta teoría y los criterios de incapacitación selectiva que implican no enviar a la cárcel a todos los agresores de la ley penal bajo un análisis de costo-beneficio, se edifica la conocida teoría americana de los three strikes and you are out, ${ }^{18}$ que, siguiendo la metáfora del juego de baseball, ofrece tres oportunidades al delincuente para evadir la prisión, al cabo de las cuales es internado a perpetuidad. Lo anterior como consecuencia de su imposibilidad de corrección.

\section{Justicia restaurativa}

La justicia restaurativa es una forma de interpretar la justicia y las vías para llegar a ella, que sitúa a la víctima en el lugar que le corresponde

\footnotetext{
14 John Braithwaite, Crime, Shame and Reintegration, (Londres: Cambridge University Press, 1989), 226.

15 Michel Foucault, La vida de los hombres infames, (Madrid: La Piqueta, 1996), 25.

16 Francisco Muñoz, "Excurso: Incapacitación: La pena de prisión como simple aseguramiento o inocuización del condenado", en Derecho y prisiones hoy coord. Francisco Javier de León (La Mancha: Ediciones de la Universidad de Castilla, 2003), 13; Andrew Von hirsch, Anthony E. Bottoms, Elizabeth Burney y P-O Wikstrom, Criminal deterrence and sentence severity, (Oxford: Hart Publishing, 1999), 9.

17 Cid, La elección del castigo, 30.

18 Manuel Cancio, "Dogmática y política criminal en una teoría funcional del delito", en El sistema funcionalista de derecho penal. Ponencias presentadas en el II Curso Internacional de Derecho Penal (Lima, 29, 31 de agosto y 01 de setiembre de 2000), 28; José Díez, La racionalidad de las leyes penales, (Madrid: Trotta, 2003), 37; Lisa Stolzenberg, y Stewart D'alessio, “Three strikes and You're out. The impact of Californian's new mandatory sentencing law on serious crime rates," Crime \& Delinquency 23, no. 4 (1997), 345.
} 
como protagonista del conflicto ocasionado y reconoce que no solo ella sufrió un menoscabo en sus intereses, sino que el conflicto también pudo transcender a la comunidad. Asimismo, pretende que el autor de la conducta lesiva asuma la responsabilidad del daño que causó, dándole la oportunidad para que repare las consecuencias adversas.

Se amplía el rango de visión de la justicia al entender que el delito no es reprochable únicamente por quebrantar la ley, sino primordialmente porque se le causó un daño a una persona y se quebrantó la paz de una comunidad. Imponer la sanción que la legislación previó para un determinado comportamiento no es suficiente para la pacificación social. Debe ampliarse el horizonte y comprender que las normas no contienen postulados de justicia implícitos e intrínsecos, es decir, no debe asumirse que la ley es en sí misma justa y que basta con su aplicación para dar a cada uno lo que le corresponde.

Esta es la razón por la que se reivindica el papel de la víctima, se reconoce que su daño es relevante para el sistema y se dispondrá de lo necesario para poder restablecerlo o repararlo. Se concibe que el delito no es otra cosa que un conflicto humano ${ }^{19}$ que debe componerse mediante el conocimiento cercano de sus causas y consecuencias. A su vez, se propone el diálogo entre las partes que se encuentran involucradas en el mismo y las fórmulas de arreglo posibles, adecuadas y necesarias para lograr una armonía entre las partes y la tranquilidad de la sociedad.

En últimas, lo que se busca es humanizar el procedimiento, retirar los rótulos de víctima, victimario, fiscal, acusado, bueno, malo, perverso, etc., y regresarles los nombres a los protagonistas de la problemática surgida. Ello permite además que los intervinientes se liberen de mitos y temores, así como de represalias y venganzas, que hacen que el infractor se sienta incluido, se perciba como parte de una sociedad que también es suya y que no debe causarle dolor. Por su parte, la víctima también debe reintegrarse a su vida volviendo a ser un miembro comunitario lejos de las etiquetas de herido que lo encadenan a vivir en el pasado doloroso.

El tema de la justicia restaurativa es uno de los de mayor crecimiento en el campo jurídico. Esta forma de solucionar conflictos nació como una alternativa a los desaciertos evidentes de la justicia penal caracterizada por su naturaleza punitiva y retributiva derivada de múltiples fuentes,

19 María Márquez-Algara, Mediación penal en México: hacia una justicia restaurativa, (México D.F.: Porrúa, 2013). 
especialmente religiosas, culturales y éticas. ${ }^{20}$ Puede afirmarse entonces que la construcción de la justicia restaurativa es de reciente creación, pero los principios en los que se basa vienen de tiempo atrás. ${ }^{21}$

Esta herramienta, tal y como se conoce hoy en día, fue tomada de los pueblos nómadas originarios, quienes en su visión comunitaria de la vida consideraron que si el infractor era parte de la colectividad, al excluirlo se afectarían el equilibrio y normal desarrollo de las actividades del grupo. Por tanto, lo mejor era someterlo a un proceso de recuperación y compelerlo a reparar los daños que había causado con su comportamiento. De esta manera, no solo se restablecía la relación entre el autor de la infracción y la víctima, sino que además se recuperaba el equilibrio al interior de la comunidad. ${ }^{22}$

Para centrar el análisis en el sistema jurídico que hoy nos rige, se marca como primer antecedente el caso del pueblo de Kitchener en Ontario, Canadá. ${ }^{23}$ Se cuenta cómo la propiedad de la población fue atacada por menores de edad. Una de estas contravenciones fue perpetrada por dos jóvenes bajo el influjo de sustancias psicoactivas, que destrozaron veintidós automóviles; se trataba de un hecho aislado que causó alarma entre los habitantes. Al ser llevados a juicio, un miembro de la secta menonita de nombre Mark Yantzi sugirió que, en consideración a que no tenían antecedentes penales, los infractores no necesitaban de un castigo, en su lugar debían asumir su responsabilidad, reparando personalmente los daños que ocasionaron.

Esta propuesta fue en principio rechazada por el juez al no estar soportada en ninguna legislación, pero al dictar la sentencia, se ordenó que los jóvenes hicieran lo recomendado por Yantzi, junto con un informe de lo encontrado. Debían dialogar con las víctimas sobre los daños que estas sufrieron. Acompañados de supervisión oficial, visitaron los hogares y negocios de los afectados, admitieron los daños y lograron acordar el

20 María Saffón y Rodrigo Uprimny, "Justicia transicional y justicia restaurativa: tensiones y complementariedades”, en ¿Justicia transicional sin transición? Verdad, justicia y reparación para Colombia, (Bogotá: Centro de Estudios de Derecho, Justicia y Sociedad -DeJusticia_, 2006).

21 Aída Kemelmajer de Carlucci, Justicia restaurativa: posible respuesta para el delito cometido porpersonas menores de edad, (Buenos Aires: Rubinzak - Culzoni Editores, 2004), 117.

22 Ibíd., 118. Esta es la Opinión del juez Beaudoin de la Corte de Quebec, expresada en la Conferencia dada en Mendoza en diciembre del año 2002.

23 Ibíd., 118-119. 
restablecimiento de las pérdidas, lo cual fue cumplido en un periodo de tres meses. Se trata entonces de un caso ejemplar sobre cómo solucionar un conflicto más allá de la aplicación rígida de la norma, reintegrando de forma efectiva al infractor con su comunidad.

\subsection{Los fines de la pena y la necesidad de repensarlos con el objetivo de buscar una reparación}

Uno de los principales motivos que dieron cabida a la restauración como forma de justicia fueron las promesas no cumplidas por parte de los modelos retributivos e inocuizadores que a lo largo de su historia solo lograron llenar y ampliar prisiones, sin alcanzar los fines de prevención general y especial para los que fueron creados, en aras de disuadir la comisión de crímenes.

$\mathrm{Al}$ respecto, es importante advertir que las teorías de la prevención general no actúan sobre los individuos sino sobre la colectividad. ${ }^{24} \mathrm{~A}$ su vez, la prevención general negativa gira en torno a una amenaza a través de la cual se espera conseguir un objetivo particular: la disuasión. ${ }^{25}$ Así, desde una visión utilitarista, la cárcel es un lugar donde se priva de la libertad a las personas que han infringido la ley con el objetivo de prevenir delitos y contener a los otros con el terror del ejemplo. ${ }^{26}$

Por su parte, la prevención general positiva busca la estabilización de la norma. Tiene tres efectos fundamentales: ${ }^{27}$ (i) Aprendizaje: la norma

24 Claus Roxin, Derecho penal. Parte General. Tomo I. Traducción y notas de Diego-Manuel Luzón Peña, Miguel Díaz y García Conlledo y Javier de Vicente Remesal. (Madrid: Civitas, 1997), 89. En palabras de Zaffaroni: "actúan sobre los que no ban delinquido". Eugenio Zaffaroni, Alejandro Alagia, y Alejandro Slokar, Derecho Penal. Parte General, (Buenos Aires: Ediar, 2000), 53.

25 Günther Jakobs, Derecho Penal. Parte General. Fundamentos y Teoría de la Imputación, Traducción de J. Cuellos y J. Serrano, (Madrid: Marcial Pons, 1995), 26; Iñaki Rivera, La cuestión carcelaria. Historia, epistemología, derecho y politica penitenciaria. Volumen I, (Buenos Aires: Editores del Puerto, 2006), 201-202 y 262; Georg Rusche, "Labor Market and Penal Sanction: Thoughts on the Sociology of Criminal Justice," en Why punish? How much? A reader on Punishment, ed. Michael Tonry, (Nueva York: Oxford University Press, 2011), 406; von Hirsch, Bottoms, Burney y Wikstrom, Criminal deterrence, 5-9.

26 Jeremías Bentham, Elpanóptico, (Madrid: La Piqueta, 1979), 34-35.

27 Roxin, Derecho penal, 91-92.

Ferrajoli, por su parte, los comprende en el reforzamiento de la fidelidad al Estado y la promoción del conformismo a las conductas. Luigi Ferrajoli, Derecho y razón. Teoría del 
tiene una motivación sociopedagógica dirigida a la colectividad, que emite un mensaje de que se ha realizado un acto prohibido; ${ }^{28}$ (ii) Confianza: relacionado con la sensación de la sociedad frente a la aplicación de la ley en contra del infractor, y (iii) Pacificación: consiste en la tranquilidad de la conciencia colectiva. Con base en esta teoría, la ciudadanía en general percibe la ejecución de la norma penal como reafirmadora de su validez y eficacia.

Tanto la prevención especial negativa como la positiva ${ }^{29}$ buscan hacer desistir al autor de futuros delitos. ${ }^{30}$ Es decir, se abstiene de comunicar a la sociedad cualquier mensaje, como lo hacen las teorías de la prevención general, y se centra exclusivamente en el individuo. La prevención especial positiva se diferencia de la negativa por las técnicas a través de las cuales se procura la consecución de este fin. Mientras que la prevención especial negativa incapacita al individuo, usando de manera preferente la pena privativa de la libertad, la prevención especial positiva tiende hacia la corrección de este, no necesariamente privándolo de su derecho de locomoción.

En este sentido, para la prevención especial negativa basta con la inocuización del sujeto, quien privado de la libertad no volverá a cometer delitos, sin tener en cuenta su futuro en libertad, omitiendo las variables que apuntan a la delincuencia intramural, con efectos que no salen de la órbita de control carcelario y otros que traspasan esos muros.

La prevención especial positiva busca la reeducación y recuperación moral del condenado. ${ }^{31}$ A partir de esta, se pretende reformar al delincuente por medio de programas que suplan las falencias que lo llevaron hacia el camino del delito. Con base en esta teoría, se busca fortalecer los valores

garantismo penal. Traducción de Perfecto Ibañez, Alfonso Ruiz, y Juan Bayón, (Madrid, Trotta, 2009), 275.

En sentido similar Máximo Pavarini, “"Economía del exceso’ y castigos excesivos”, Bulletin de la Société Internationale de Défense Sociale pour une Politique Criminelle Humaniste - Cabiers de Defense Sociale, 2004, 241.

28 Elena Larrauri, Introducción a la criminología y al sistema penal, (Madrid, Trotta, 2015), 55.

29 Se sigue lo argumentado en Norberto Hernández, El derecho penal de la cárcel. Una mirada al contexto colombiano con base en el giro punitivo y la tendencia al mayor encarcelamiento, (Bogotá: Siglo del Hombre Editores, Universidad de los Andes, Universidad EAFIT, 2018), 296-297.

30 Roxin, Derecho penal, 85.

31 Ferrajoli, Derecho y razón, 226. 
éticos y sociales elementales frente a las acciones que lesionan bienes y se dirigen contra esos valores. ${ }^{32}$

Puede verse entonces cómo, de todos los fines que justifican la privación de la libertad, únicamente el de la retribución justa fue satisfecho por los sistemas de justicia alrededor del mundo, sin que con ello se tengan en la actualidad sociedades más pacíficas o igualitarias; por el contrario, los índices de violencia son cada vez mayores. En palabras de Foucault "hay que concebir un sistema penal como un aparato para administrar diferencialmente los legalismos, y no, en modo alguno, para suprimirlos todos". ${ }^{33}$

La lógica desde la cual actúa la administración de justicia centra su atención en el delincuente. Es un proceso creado por y para él, que permite y recrea, desde el inicio, un enfrentamiento con la víctima que le realiza señalamientos de responsabilidad penal mientras aquél intenta a toda costa defenderse, haciendo uso de todas las garantías sustanciales y procesales que se crearon a su favor. Garantías que no son más que matices que imprimen un tinte de humanidad a un acto tan irracional como imponer un castigo a una persona.

Mientras tanto, a la víctima se le deja de lado con las consecuencias, dolores y afectaciones producidas por el delito sin ningún tipo de tratamiento o consideración. Durante el juicio, se le tiene como el principal testigo de una causa que ya dejó de ser suya para ser el caso del fiscal, quien lo presenta ante un juez pasando a ser un conflicto de terceros que no tuvieron participación en la génesis de la violación del derecho de esta víctima ni de las cientos o miles que se encuentran en sus gavetas.

Esta situación que parece tan propia de la justicia penal, en realidad permeó la totalidad de la administración de justicia, que se encuentra casi en cualquier litigio, local o internacional. El siDH no es una excepción a esta regla. Por el contrario, el mismo se creó a imitación de estos modelos locales y, como se verá a lo largo de este documento, se replicaron igualmente sus consecuencias.

Se observa cómo la institucionalidad estatal se apropió del conflicto sin importar si víctima y victimario tuvieron en algún momento el interés de conciliar. A la víctima se le silencia y solo se le escucha en lo que sea relevante para el proceso judicial sin que pueda entender los

\footnotetext{
32 Zaffaroni, Alagia y Slokar, Derecho Penal, 54.

33 Michel Foucault, Obrar mal, decir la verdad, (Bueno Aires: Siglo xxi Editores, 2014), 93.
} 
términos, leyes ni procedimientos. Ella mira pasmada desde su banquillo y en tal virtud, el juzgador, al decidir el caso, aplica la ley suponiendo en ella contenidos de justicia, pero no da una respuesta efectiva a los pedimentos de la víctima, ya que nunca supo de cuáles se trataba. Luego, el juez "no ha causado ningún bien a nadie: ni a la víctima, ni al infractor ni a la sociedad global". ${ }^{34}$ Si no se ha hecho ningún bien a la víctima más allá de la efímera y mentirosa sensación de victoria, dentro de la lógica de perdedores y ganadores sobre la que se edifican los procesos judiciales, mucho menos al infractor a quien desde el inicio se le estaba persiguiendo para devolverle, y hasta multiplicarle, el mal que causó.

Aquí surge otra de las principales problemáticas de la aplicación rígida y severa de la ley penal: las cárceles. Estas son la prueba viviente del fracaso de los modelos punitivos que privilegian su uso, que lejos de lograr la resocialización y la prevención general y especial para las que fueron creadas solo quebrantan los derechos humanos, en especial la dignidad humana de los internos. ${ }^{35}$ Las prisiones rebasaron los límites con los que fueron diseñadas, se convirtieron en un caos que escapa de las manos del Estado y pasaron a ser centros especializados de crimen y violencia lo cual, sumado al hacinamiento que se vive en su interior, principalmente en países no desarrollados, las convierte en lugares desde todo punto de vista infrahumanos. ${ }^{36}$

\subsection{Fines de la justicia restaurativa}

Faget $^{37}$ sostiene que la justicia restaurativa es la conjunción de tres líneas ideológicas diversas. La primera muestra el quebranto de la regulación institucional y la comunidad que se encuentra sin rumbo y que requiere

34 Elías Neuman, La mediación penaly la justicia restaurativa, (México D. F.: Porrúa, 2005), 18.

35 En el mismo sentido Norberto Hernández, "El fracaso de la resocialización en Colombia”, Revista de Derecho, no. 49 (2018).

36 Al respecto el Comité de Derechos Humanos de la Organización de las Naciones Unidas señala que al interior de los centros penitenciarios se lleva a cabo en condiciones insalubres, lo que amenaza los derechos a la salud y a la vida de los reclusos. Asimismo, precisó que el hacinamiento constituye la principal problemática; el Comité de Derechos Humanos ha sido enfático en establecer que este es una fuente de violación del artículo 10.

En el mismo sentido el caso Kalashnikov c. Rusia (2002) del Tribunal Europeo de Derechos Humanos.

37 Jacques Faget, “La meditación. Essai de politique pénale”, Droit et Society 41, (1999), 188. 
atención. La segunda puso en evidencia las consecuencias negativas que imponían los sistemas penales al delincuente. La tercera, bajo la bandera del posicionamiento de los derechos humanos, tiende a desarrollar mecanismos protectores del delincuente y de la víctima.

Es claro que, al tratarse de una forma diferente de abordar el conflicto generado por el acaecimiento de un delito o una violación a los derechos humanos, el fin primordial de la justicia restaurativa es que se protejan y cumplan, al máximo, los intereses de la víctima que se generaron con la conducta lesiva. ${ }^{38}$ Para ello, la víctima debe tener la posibilidad de ser escuchada, de poder contar y narrar sus historias sin la premura, tiempos y espacios limitados de un proceso judicial. ${ }^{39}$ Es de la mayor importancia que se conozca desde la propia víctima cuáles son sus necesidades y expectativas, ya que ningún daño sufrido por una persona puede ser restituido mediante una suma de dinero. Debe existir un acuerdo frente a las formas de reparar el daño que se le ocasionó, en la medida y forma en que la víctima indique sentirse mejor desagraviada. ${ }^{40}$

Esta narrativa de la víctima constituye, además, una forma de superar el conflicto a nivel psicológico al generar un reconocimiento de la persona de la víctima y de su dolor al salir del silencio y convertir su relato en una memoria transformadora. La víctima puede cambiar lo vivido si de forma guiada se le brinda o potencializa su capacidad de transmitir lo sucedido si se le enseña a observar los cambios desde el presente y el futuro que puede construirse, no solo desde el pasado que ya pasó y no puede cambiarse. Se crea de ese modo una distancia psicológica de la acción cuando se habla de algo doloroso. ${ }^{41}$

Otra de las finalidades resulta ser la de recuperar al ofensor en aras de prevenir de manera efectiva la reincidencia con respeto de sus garantías constitucionales. Este otro interés debe interactuar con los de la víctima comoquiera que la justicia restaurativa esté orientada a darle prioridad a esta última. Entonces, "[la] pregunta central no es ¿Quién debe ser sancionado?; ¿con que pena?, sino ¿Qué debe hacerse para reparar el daño?”. ${ }^{42}$

\footnotetext{
38 Kemelmajer de Carlucci, Justicia restaurativa, p. 146.

39 Neuman, La mediación penal, 49.

40 Ibíd.

41 Carlos Martín, Manual sobre perspectiva psicosocial en la investigación de derechos humanos, (Bilbao: Instituto Hegoa - UPV/EHU, 2010).

42 Kemelmajer de Carlucci, Justicia restaurativa, 146.
} 
Para poder prevenir la reincidencia del infractor, resulta mucho más favorable un escenario en el que lejos de reprochar la conducta cometida, se le acerca a su víctima con el fin de que tome "conciencia sobre los daños que causó, reconocer su responsabilidad e intentar reparar ese daño". ${ }^{43}$ Deben entonces abandonarse visiones de la justicia como la impositora de penas, para empezar a verla y entenderla como aquella vía mediante la cual pueden solucionarse conflictos y repararse las heridas. ${ }^{44}$

Ahora bien, el fin más importante de la justicia restaurativa es la reparación. Lo primero que debe aclararse es que no se trata del concepto comúnmente estudiado en la teoría general del derecho: una compensación de contenido monetario ya que, aun cuando la incluye, va más allá al tener un contenido ético que la convierte en un acto complejo. ${ }^{45}$ Lo esperado es que se restauren los lazos sociales entre víctima y victimario y los de estos con la comunidad, teniendo como punto de partida el restablecimiento entre el infractor y el agredido. ${ }^{46}$

Insistimos, la reparación debe verse en sentido amplio, esto es, más allá de la compensación en dinero, pues existen otras medidas que contribuyen a cicatrizar las heridas producidas por el daño. ${ }^{47}$ Para muchos de los agredidos, el hecho de que el infractor tome consciencia de su responsabilidad y manifieste un sincero arrepentimiento es de la mayor importancia para su sanación. ${ }^{48}$ Esta circunstancia sin duda alguna resulta ser más aliviadora de dolor que el tener que observar en el escenario de un juicio a un victimario que todo el tiempo está defendiéndose mediante la negación de los hechos o una tosca justificación.

Con base en lo anterior, Retzinger y Scheff ${ }^{49}$ clasifican la reparación en (i) material y (ii) simbólica. La primera se trata de un arreglo que alcanzan las dos partes en conflicto y que, se repite, puede consistir en una cantidad de dinero o en la prestación de algún tipo de servicio. La

\footnotetext{
43 Saffón y Uprimny, "Justicia transicional y justicia restaurativa”, 119.

44 Kemelmajer de Carlucci, Justicia restaurativa, 147.

45 Ibíd.

46 Ibíd., 153.

47 Sobre las distintas formas de reparación, ver Norberto Hernández, "Rol probatorio del apoderado de las víctimas dentro del incidente de reparación integral”, Revista Diálogos de Saberes, no. 33 (2010).

48 Kemelmajer de Carlucci, Justicia restaurativa, 154.

49 Citados por Kemelmajer de Carlucci, Justicia restaurativa, 155.
} 
simbólica es un acto menos perceptible que se trata de la manifestación de "una vergüenza genuina por lo hecho y remordimiento por sus acciones". ${ }^{50}$ Esta forma de reparación genera que la víctima realice un acercamiento que la conduzca hacia el perdón.

\section{La justicia restaurativa en el SIDH a propósito de las soluciones amistosas}

Pese a que dentro del SIDH no existe un auténtico mecanismo de justicia restaurativa para la solución de las controversias que llegan a él, ni se usan de forma metódica sus técnicas, la Corte Interamericana de Derechos Humanos (CorteIDH) se viene acercando a esta. En sus fallos ordena una serie de medidas reparativas que se diferencian de las que se establecen dentro de un proceso o trámite incidental de naturaleza civil en un tribunal local, por cuanto estas abarcan a la comunidad, tomando medidas que están dirigidas a erradicar las condiciones de desigualdad o vulnerabilidad que al interior de los Estados generan violaciones a los derechos humanos de forma orgánica y que, se reitera, trascienden al sujeto e incluyen el entorno.

Todo esto puede encuadrarse como un tratamiento restaurativo en las decisiones de la CorteidH aun sin la celeridad, participación, comunicación y compromiso característicos de la justicia restaurativa. En efecto, este tribunal internacional a lo largo de su jurisprudencia ha ido más allá de lo ordenado por la Convención Americana de Derechos Humanos ${ }^{51}$ buscando, al igual que la visión restaurativa, el logro de la paz social.

Si se observa el desarrollo jurisprudencial de la CorteIDH, puede verse con claridad que ella realiza un examen contextual amplio y completo del escenario en el que se desenvolvieron las violaciones a los derechos objeto de litigio. En ese mismo contexto realiza, una vez declarada la responsabilidad por parte del Estado, las reparaciones a que haya lugar para el resarcimiento de los perjuicios a la víctima y va más allá al tomar medidas tendientes a eliminar las formas de vulneración estructurales

\footnotetext{
50 Kemelmajer de Carlucci, Justicia restaurativa, 155.

51 "Artículo 63. 1. Cuando decida que hubo violación de un derecho o libertad protegidos en esta Convención, la Corte dispondrá que se garantice al lesionado en el goce de su derecho o libertad conculcados. Dispondrá, asimismo, si ello fuera procedente, que se reparen las consecuencias de la medida o situación que ha configurado la vulneración de esos derechos y el pago de una justa indemnización a la parte lesionada".
} 
identificadas en la situación fáctica recreada (pese a solo aceptar peticiones individuales), imponiendo parámetros de restauración de derechos e incluso de justicia social, para lograr mediante sus decisiones que los Estados realicen labores de distribución efectiva de recursos. ${ }^{52}$

No obstante, no todos los casos logran un pronunciamiento por parte de la CorteidH; los que lo hacen llegan a estas medidas luego de varios años de litigio que se suman a los muchos otros recorridos en las jurisdicciones locales. Por ello, el sIDH previó dentro de su funcionamiento una herramienta alterna al procedimiento tradicional que le permite al Estado y al peticionario solucionar de forma acordada la problemática llevada a su seno. Es así como las soluciones amistosas fueron previstas desde el origen del sistema en el instrumento convencional como una forma de terminación anticipada, que puede ser considerada como una herramienta de justicia restaurativa.

Las mismas formas de reparación logradas en sede de la CorteIDH pueden ser acordadas dentro del procedimiento de soluciones amistosas cuyos informes si bien no interpretan el contenido y alcance de los derechos al carecer la Comisión de facultades jurisdiccionales, cubren de manera satisfactoria las expectativas que tiene la víctima al momento de presentar una petición al SIDH. Estas aspiraciones deben ser el único y más importante objetivo en cualquier procedimiento de protección de derechos, máxime cuando dentro de las soluciones amistosas el Estado puede igualmente hacer una aceptación de su responsabilidad.

En general todos los casos que terminan con un informe de solución amistosa son muestra del logro de la justicia mediante la restauración. Pueden destacarse algunos como el caso Verbitsky dentro del cual el peticionario fue condenado por la Corte Suprema de Justicia argentina por el delito de desacato al incluir en un artículo la expresión "asqueroso" para referirse a una entrevista dada por el ministro de la Corte Suprema,

$52 \mathrm{Al}$ respecto puede verse la sentencia del Caso masacre plan de Sánchez. c. Guatemala de 19 de noviembre de 2004 en la cual se ordena al Estado proveer de una vivienda adecuada a las víctimas sobrevivientes, así como el mantenimiento y mejoras en el sistema de comunicación vial, sistema de alcantarillado y agua potable, el establecimiento de un centro de salud, entre otras. En el mismo sentido la sentencia Comunidad Mayagna (Sumo) Awas Tingni c. Nicaragua de 31 de agosto de 2001 ordenó que "que el Estado debe invertir, por concepto de reparación del daño inmaterial, en el plazo de 12 meses, la suma total de US\$ 50.000 en obras o servicios de interés colectivo en beneficio de la Comunidad Mayagna (Sumo) Awas Tingni, de común acuerdo con esta”. 
Augusto Belluscio. La conducta se encontraba tipificada como delito en el artículo 244 del Código Penal. Mediante el acuerdo de solución amistosa se logró que a través de la ley nacional No 24198 se derogara esta disposición y se revocara el fallo condenatorio proferido en contra del periodista Horacio Verbitsky.

Otro ejemplo sobresaliente es el caso Niños capados de Marañón c. Brasil. Se refiere a niños castrados y asesinados en la región de la Gran São Luís, Estado de Marañón. Mediante la solución amistosa, además de la aceptación de responsabilidad por parte del Estado, se acuerdan campañas de sensibilización y modificaciones legislativas y se incluyó la implementación de políticas públicas tendientes a erradicar y prevenir la violencia sexual en niños, niñas y adolescentes; así como la construcción de escuelas y la inclusión de actividades culturales y deportivas en todas las instituciones de la rede estadual de enseñanza.

Como se advirtió, mediante la justicia restaurativa se centra la atención en la afectación que se causó y en cómo esta puede ser reparada, pretendiendo que la víctima continúe con su proyecto de vida, mirando al futuro y no al pasado, todo lo cual se aplica en las decisiones de fondo del SIDH, luego, los resultados alcanzados en estas y en el mecanismo autocompositivo $^{53}$ resultan igualmente resarcitorios de la violación alegada. La diferencia radicaría en que en el primero, la víctima, además de correr el riesgo que su caso nunca sea llevado a la CorteIDH o que se produzca un fallo contrario a sus intereses, pierde la oportunidad de participar en la elaboración de esas medidas reparativas, de realizar las peticiones que más se ajusten a sus necesidades, así como de tener mayor certeza del cumplimiento del mismo, comoquiera que el Estado al haber participado en la producción de estas se compromete, en cumplimiento de la buena fe que le obliga, a acciones que se encuentran a su alcance.

Más que una resocialización o readaptación social del Estado para con sus nacionales debe buscarse una "rehumanización" o "reinternacionalización" del mismo. Así, se encontrará acorde con los requerimientos de la comunidad no solo regional sino global en materia de protección y defensa de los derechos humanos.

53 Desde su planteamiento en la Convención, se vislumbra que su naturaleza se encuentra lejos de la heterocomposición, entendida como la intervención de un tercero para dar solución al conflicto planteado de forma autónoma sin consideración ni participación de los agentes en conflicto. 
Una sentencia condenatoria no es el mejor camino para lograrlo, tal y como sucede con el acusado en el proceso penal; el Estado que fue vencido en juicio no tiene mayor motivación para el cumplimiento de la sentencia. De allí que se realicen cumplimientos parciales teniendo por observado en primer término la indemnización económica. Las reparaciones simbólicas se realizan en ocasiones casi con cinismo, levantando monumentos precarios, carentes del sentimiento que debiera imprimírseles, en pequeñas dimensiones y/o en lugares lejanos. ${ }^{54}$

El camino de la justicia restaurativa abre nuevas posibilidades para que sea el mismo Estado el que acepte la conculcación de los derechos de sus asociados y busque, junto con sus víctimas directas, la forma de lograr resarcir el daño producido. Cuando el propio autor del perjuicio es quien establece que debe ejercer un acto positivo por este, que él reconoció y asumió que causó, se reafirma la vigencia de la norma, al tomarse conciencia de la protección intrínseca de la misma. De esta manera, los deberes contenidos en la Convención y en los demás instrumentos internacionales protectores de los derechos humanos se traducen en una convicción, en un deber ser que el Estado se arroga para sí de forma reflexiva y sin imposición alguna.

El ente abstracto creado para brindar protección a sus ciudadanos se materializa convirtiéndose en un sujeto más humano, más cercano a sus nacionales y más comprometido con el logro de la armonía social. Asimismo, resulta más reparador para la víctima el reconocimiento del daño por quien se lo causó y la voluntad de realizar las acciones necesarias para enmendarlo.

El SIDH debe entonces dar una mirada hacia nuevas formas de interpretar la justicia y su aplicación. Aun cuando exista el mecanismo de soluciones amistosas, debe robustecerse y mutar en un verdadero ejercicio de justicia restaurativa con todos los requerimientos e implicaciones explicados. Debe darse una respuesta a las miles de víctimas que acuden año tras año a la CIDH en busca de protección, solo para el año 2013 fueron recibidas un total de 2061 peticiones y en el mismo año solo

54 Un ejemplo es la sentencia "Campo algodonero" en donde la CorteIDH ordenó levantar un monumento en memoria de las mujeres víctimas de homicidios por razones de género en Ciudad Juárez y una vez realizado, fue abucheado por las familias de las víctimas quienes lo calificaron de "inconcluso" y no acudieron al acto de inauguración. 
se realizaron 6 informes de solución amistosa y se presentaron 11 casos ante la CorteIDH. ${ }^{55}$

Como se advirtió con anterioridad, la CorteIDH es progresista en su jurisprudencia, al incluir un análisis más amplio del contexto en el que se desarrollaron las violaciones a los derechos humanos alegadas. En esa misma línea, intenta brindar correctivos permeados con un tinte de justicia social, que propenden por minimizar las condiciones de desigualdad estructurales al interior de los países. Estas medidas trascienden el orden pecuniario y buscan que la víctima sea reparada de manera integral con la adopción de medidas en diversos campos de aplicación, que tienden hacia una justicia restaurativa al interior del SIDH, dentro de las cuales encontramos:

i) Restablecimiento al proyecto de vida. La CorteIDH estima que existe un daño diferente del emergente y el lucro cesante, relacionadas con las expectativas que las personas se fijan razonablemente y la libertad que tiene para realizarlas. Por el acaecimiento de la situación violatoria de derechos humanos la persona ve disminuidas sus facultades o las condiciones generales que le obligan a alterar su vida cotidiana y sus proyectos. Así lo expresó el alto tribunal internacional en la sentencia de reparaciones del Caso Loaiza Tamayo c. Perú:

[El] "daño al proyecto de vida", entendido como una expectativa razonable y accesible en el caso concreto, implica la pérdida o el grave menoscabo de oportunidades de desarrollo personal, en forma irreparable o muy difícilmente reparable. Así la existencia de una persona se ve alterada por factores ajenos a ella, que le son impuestos en forma injusta y arbitraria, con violación de las normas vigentes y de la confianza que pudo depositar en órganos de poder público obligados a protegerla y a brindarle seguridad para el ejercicio de sus derechos y la satisfacción de sus legítimos intereses. Por todo ello, es perfectamente admisible la pretensión de que se repare, en la medida posible y con los medios adecuados para ello, la pérdida de opciones por parte de la víctima, causada por el hecho ilícito.

55 Comisión Interamericana de Derechos Humanos, "El sistema de peticiones y casos individuales", Informe anual 2013, Capítulo II, https://www.oas.org/es/cidh/docs/anual/2013/ docs-es/InformeAnual-Cap2-A-B.pdf 
En este caso de 1998, la CorteIDH indicó que no contaba con criterios doctrinales ni jurisprudenciales para tasar este tipo de daño y concluyó afirmando que el acceso a instancias internacionales, así como la sentencia misma constituían formas de reparación. No fue sino hasta el 2001, cuando resolvió el Caso Cantoral Benavides c. Perú, que reafirmó la doctrina expuesta y ordenó como forma de reparación el otorgamiento de una beca de educación superior en el programa que la víctima eligiera. Estas medidas tendientes a minimizar el impacto de la violación al proyecto de vida se clasifican de forma general dentro de las medidas de satisfacción.

A continuación, se relacionan otras decisiones de la CorteIDH en torno al restablecimiento del proyecto de vida:

Tabla 1. Decisiones de la CorteIDH sobre el daño al proyecto de vida

\begin{tabular}{|c|c|c|}
\hline Sentencia & Año & Daño al proyecto de vida \\
\hline $\begin{array}{l}\text { Villagrán } \\
\text { Morales c. } \\
\text { Guatemala }\end{array}$ & 1999 & Voto razonado. Se hace referencia a la sentencia. \\
\hline $\begin{array}{l}\text { Maritza } \\
\text { Urrutia c. } \\
\text { Guatemala }\end{array}$ & 2003 & $\begin{array}{l}\text { Es evidente para la Corte por otra parte, que los hechos de este caso ocasio- } \\
\text { naron una alteración en el curso que habría seguido normalmente la vida } \\
\text { de Maritza Urrutia, dado que luego de los hechos se vio forzada a salir del } \\
\text { país y permanecer lejos de su familia, lo que le causó angustia y tristeza. } \\
\text { Es razonable concluir que las aflicciones sufridas por la víctima se extiendan } \\
\text { a los miembros más cercanos de la familia, particularmente aquéllos que } \\
\text { tenian un contacto afectivo estrecho con la víctima. No se requiere prueba } \\
\text { para llegar a esta conclusión. }\end{array}$ \\
\hline $\begin{array}{l}\text { Tibic. Ecua- } \\
\text { dor }\end{array}$ & 2004 & $\begin{array}{l}\text { En el caso Loayza Tamayo, la Corte emprendió el examen de un tema que } \\
\text { aún requiere elaboración y consolidación: el proyecto de vida. Se trata de las } \\
\text { oportunidades, chances, expectativas. Está vinculado, como se dijo en ese } \\
\text { caso, con metas razonables, esperanzas fundadas, proyectos accesibles, que } \\
\text { constituyen, en su conjunto, el derrotero para el desarrollo de la persona, } \\
\text { deliberado y factible, a partir de ciertas condiciones que lo apoyan y justifican. } \\
\text { Agréguese la posibilidad de que exista una decisión concreta por parte del } \\
\text { titular de los derechos afectados, decisión sustentada en aquellos elementos, y } \\
\text { no apenas en suposiciones, presunciones o inferencias del observador externo. }\end{array}$ \\
\hline $\begin{array}{l}\text { Gutiérrez Soler } \\
\text { c. Colombia }\end{array}$ & 2005 & $\begin{array}{l}\text { La Comisión alegó que el proyecto de vida del señor Wilson Gutiérrez } \\
\text { Soler ha sido "destruido por la impunidad de los responsables y la falta de } \\
\text { reparación". Por su parte, los representantes argumentaron que los hechos } \\
\text { del caso sub judice cambiaron "radicalmente" su vida, y causaron la } \\
\text { ruptura "de su personalidady sus lazos familiares". }\end{array}$ \\
\hline
\end{tabular}

Continúa 


\begin{tabular}{|c|c|c|}
\hline Sentencia & Año & Daño al proyecto de vida \\
\hline & & 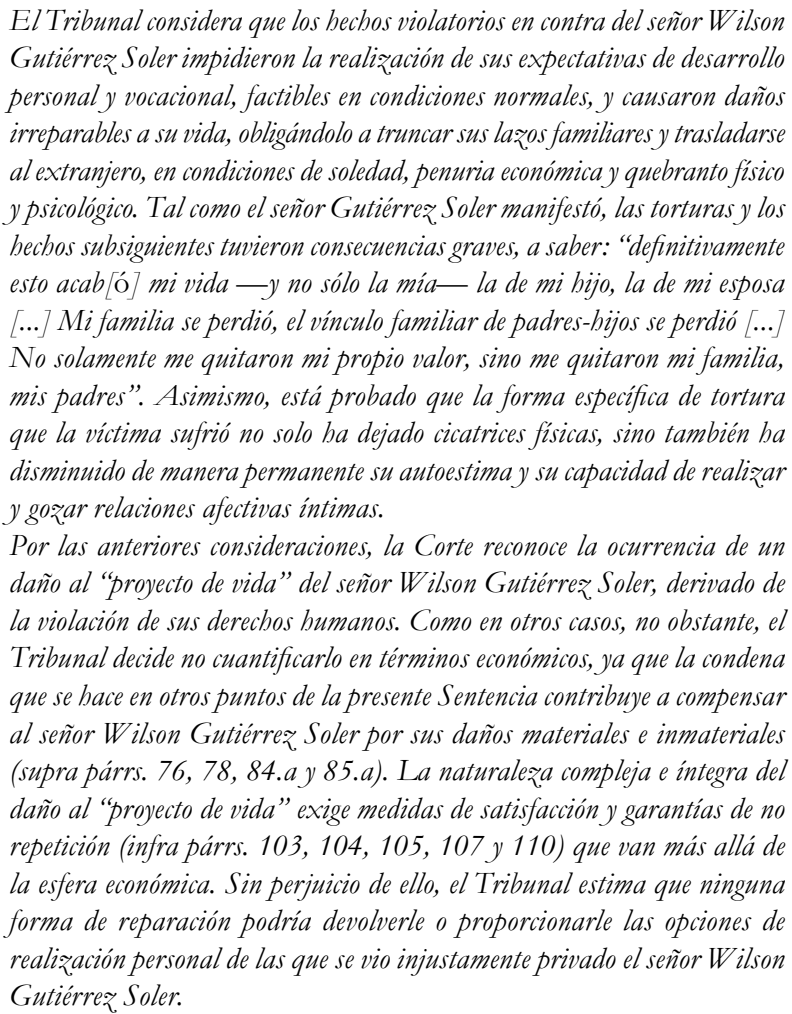 \\
\hline $\begin{array}{l}\text { Gómez Palo- } \\
\text { mino c. Perú }\end{array}$ & 2005 & $\begin{array}{l}\text { Este Tribunal ha tenido por demostrado (supra párr. 54.23) que los hechos } \\
\text { del presente caso afectaron la continuidad de los proyectos de vida del her- } \\
\text { mano y las hermanas menores de la víctima, para quienes el futuro se volvió } \\
\text { incierto. Luego de producirse la desaparición del señor Gómez Palomino, } \\
\text { todos ellos interrumpieron sus estudios, no solo debido a factores económicos, } \\
\text { sino también, como lo señala la perito, María del Pilar Raffo Lavalle de } \\
\text { Quiñones (supra párr. 48. c), a consecuencia de factores emocionales como } \\
\text { la depresión, la preocupación y la tristeza. } \\
\text { Consecuentemente, este Tribunal dispone, como medida de satisfacción, que } \\
\text { el Estado deberá proporcionar todas las facilidades materiales necesarias } \\
\text { a fin de que, en el caso que lo deseen, los señores Emiliano, Mónica, Rosa } \\
\text { y Margarita, todos Palomino Buitrón, puedan participar en programas } \\
\text { especiales de educación para adultos que les permitan culminar sus estudios } \\
\text { primarios y secundarios, según sea el caso. Estos programas educativos se } \\
\text { desarrollarán con adecuación de borario, de manera que en lo posible no } \\
\text { interfieran con las actividades laborales de los beneficiarios. }\end{array}$ \\
\hline
\end{tabular}




\begin{tabular}{|c|c|c|}
\hline Sentencia & Año & Daño al proyecto de vida \\
\hline $\begin{array}{l}\text { Masacre } \\
\text { Mapiripán } \\
\text { c. Colombia. } \\
\text { Voto razonado } \\
\text { Gustavo Zafra }\end{array}$ & 2005 & $\begin{array}{l}\text { El municipio de Mapiripán jamás volverá a ser el mismo. El municipio, } \\
\text { el sujeto colectivo con personería jurídica que la Constitución de Colombia } \\
\text { define como la "entidad territorial fundamental", perdió en este caso su } \\
\text { identidad anterior a la masacre. a) Ante la evidente dificultad de retorno } \\
\text { en el caso de las víctimas que sobrevivieron, el Estado está en la obligación } \\
\text { de garantizar que estas personas tengan la oportunidad de rehacer la vida } \\
\text { familiar, laboral, y personal. b) Si a lo anterior lo llamamos proyecto } \\
\text { de vida, o recuperación de la identidad personal, o libre desarrollo de la } \\
\text { personalidad, es un debate conceptual importante. Sin embargo, lo práctico } \\
\text { para el cumplimiento de la sentencia, es que el Estado asuma seriamente } \\
\text { la obligación jurídica de capacitar y prestar la ayuda médica y psicológica } \\
\text { a estas personas, en Mapiripán o en el municipio donde se domicilien. c) } \\
\text { En experiencias traumáticas semejantes se ha establecido la capacidad de } \\
\text { recuperación de las personas que, a través de procesos de resiliencia, resisten } \\
\text { al dolory desarrollan una capacidad de superarlo. }\end{array}$ \\
\hline $\begin{array}{l}\text { Baldeón Gar- } \\
\text { cía c. Perú }\end{array}$ & 2006 & $\begin{array}{l}\text { Analizados los argumentos de los representantes y de la Comisión, así como } \\
\text { el acervo probatorio del presente caso, se desprende que los padecimientos } \\
\text { psicológicos y emocionales de los familiares del señor Baldeón García, } \\
\text { derivados de la situación de las violaciones declaradas en el presente fallo, } \\
\text { perduran hasta abora y perjudican sus respectivos proyectos de vida. Para } \\
\text { ello, esta Corte estima, como lo ha hecho en otras oportunidades, que las } \\
\text { reparaciones también deben comprender tratamiento psicológico y psiquiátrico } \\
\text { a los familiares del señor Baldeón Garcia, si ellos así lo desearan. }\end{array}$ \\
\hline $\begin{array}{l}\text { Masacre La } \\
\text { Rochela c. } \\
\text { Colombia }\end{array}$ & 2007 & $\begin{array}{l}\text { ElEstado aceptó parcialmente su responsabilidad. Se acordaron las medidas } \\
\text { de restablecimiento del proyecto de vida. } \\
\text { Respecto al daño al proyecto de vida de las víctimas y sus familiares } 1 . \\
\text { Como una obligación de medio, el Ministerio de Educación, con apoyo del } \\
\text { Programa Presidencial de Derechos Humanos y Derecho Internacional } \\
\text { Humanitario, continuará gestionando auxilios educativos (becas) para los } \\
\text { familiares de las víctimas, en instituciones de educación secundaria, técnica } \\
\text { y superior de carácter público o privado en Colombia. Los representantes } \\
\text { de las víctimas remitirán, en el plazo de un mes, el listado de los familiares } \\
\text { de las víctimas que desean beneficiarse con esta gestión, el cual contendrá los } \\
\text { siguientes datos: } 1 . \text { Nombre completo del aspirante; } 2 \text {. Nivel educativo, asi } \\
\text { como elprograma, carrera, especialización o curso al que aspira; } 3 \text {. Tres (3) } \\
\text { opciones de posibles instituciones educativas donde desea cursar sus estudios. }\end{array}$ \\
\hline $\begin{array}{l}\text { Masacre Las } \\
\text { Dos Erres c. } \\
\text { Guatemala }\end{array}$ & 2009 & $\begin{array}{l}\text { Aceptación de responsabilidad. La Corte estima que, con motivo de la } \\
\text { denegación de justicia en perjuicio de las victimas de muy graves violaciones } \\
\text { a derechos humanos, como lo es una masacre, se presentan una diversidad } \\
\text { de afectaciones tanto en la esfera individual como colectiva. En este sentido, } \\
\text { resulta evidente que las victimas de una impunidad prolongada sufran dis- } \\
\text { tintas afectaciones por la búsqueda de justicia no solo de carácter material, }\end{array}$ \\
\hline
\end{tabular}

Continúa 


\begin{tabular}{|c|c|c|}
\hline Sentencia & Año & Daño al proyecto de vida \\
\hline & & $\begin{array}{l}\text { sino también otros sufrimientos y daños de carácter psicológico, físico y en } \\
\text { su proyecto de vida, así como otras posibles alteraciones en sus relaciones } \\
\text { sociales y la dinámica de sus familias y comunidades. } \\
\text { Este Tribunal ha señalado que estos daños se intensifican por la falta de } \\
\text { apoyo de las autoridades estatales en la búsqueda efectiva e identificación de } \\
\text { los restos, y la imposibilidad de honrar apropiadamente a sus seres queri- } \\
\text { dos. Frente a ello, la Corte ha considerado la necesidad de otorgar diversas } \\
\text { medidas de reparación, a fin de resarcir los daños de manera integral, por } \\
\text { lo que además de las compensaciones pecuniarias, las medidas de satisfac- } \\
\text { ción, restitución, rehabilitación y garantías de no repetición tienen especial } \\
\text { relevancia por la gravedad de las afectaciones y el carácter colectivo de los } \\
\text { daños ocasionados. Este Tribunal ha establecido que las reparaciones deben } \\
\text { tener un nexo causal con los hechos del caso, las violaciones declaradas, los } \\
\text { daños acreditados, así como con las medidas solicitadas para reparar los } \\
\text { daños respectivos. Por lo tanto, la Corte deberá observar dicha concurrencia } \\
\text { para pronunciarse debidamente y conforme a derecho. De acuerdo con las } \\
\text { consideraciones sobre el fondo y las violaciones a la Convención declaradas } \\
\text { en los capitulos correspondientes, asi como a la luz de los criterios fijados en } \\
\text { la jurisprudencia del Tribunal en relación con la naturalezay alcances de la } \\
\text { obligación de reparar, la Corte procederá a analizar tanto las pretensiones } \\
\text { presentadas por la Comisión y los representantes, como los argumentos } \\
\text { del Estado al respecto, con el objeto de disponer las medidas tendientes a } \\
\text { reparar dichas violaciones. }\end{array}$ \\
\hline $\begin{array}{l}\text { Mejía Idrovo c. } \\
\text { Ecuador }\end{array}$ & 2011 & $\begin{array}{l}\text { La jurisprudencia internacional y en particular de la Corte, ha establecido } \\
\text { reiteradamente que la sentencia constituye per se una forma de reparación. } \\
\text { No obstante, considerando las circunstancias del caso sub judice, en vista } \\
\text { de las afectaciones al señor Mejía Idrovo, derivado de las alteraciones a sus } \\
\text { condiciones y proyecto de vida, expectativas de desarrollo profesional, y las } \\
\text { restantes consecuencias de orden inmaterial sufridas como consecuencia de } \\
\text { las violaciones de los articulos } 25.1 \text { y } 25.2 \text { c) de la Convención Americana, } \\
\text { declaradas en perjuicio de la victima, la Corte estima pertinente fjar las } \\
\text { siguientes medidas. }\end{array}$ \\
\hline $\begin{array}{l}\text { Furlán c. } \\
\text { Argentina }\end{array}$ & 2012 & $\begin{array}{l}\text { B.1.2) Rehabilitación en relación con el proyecto de vida. Respecto al pre- } \\
\text { sunto "daño a la vida de relación" alegado por los representantes en el caso } \\
\text { de Sebastián Furlán, tomando en cuenta el contenido del alegato, la Corte } \\
\text { interpreta esta expresión en relación con el denominado daño al "proyecto de } \\
\text { vida", que atiende a la realización integral de la persona afectada, conside- } \\
\text { rando su vocación, aptitudes, circunstancias, potencialidades y aspiraciones, } \\
\text { que le permiten fijarse razonablemente determinadas expectativas y acceder } \\
\text { a ellas. El proyecto de vida se expresa en las expectativas de desarrollo } \\
\text { personal, profesionaly familiar, posibles en condiciones normales. Esta Corte } \\
\text { ha señalado que el "daño al proyecto de vida" implica la pérdida o el grave } \\
\text { menoscabo de oportunidades de desarrollo personal, en forma irreparable o }\end{array}$ \\
\hline
\end{tabular}

ACDI, Bogotá, ISSN: 2027-1131/ISSNe: 2145-4493, Vol. 13, pp. 47-78, 2020 


\begin{tabular}{|c|c|l|}
\hline Sentencia & Año & \multicolumn{1}{|c|}{ Daño al proyecto de vida } \\
\hline & $\begin{array}{l}\text { muy difícilmente reparable. Dicho daño se deriva de las limitaciones sufridas } \\
\text { por una persona para relacionarse y gozar de su entorno personal, familiar } \\
\text { o social, por lesiones graves de tipo físico, mental, psicológico o emocional. } \\
\text { La reparación integral del daño al "proyecto de vida" generalmente requiere } \\
\text { medidas reparativas que vayan más allá de una mera indemnización mone- } \\
\text { taria, consistentes en medidas de rehabilitación, satisfaccióny no repetición. } \\
\text { En algunos casos recientes la Corte ha valorado este tipo de daño y lo ha } \\
\text { reparado. Asimismo, el Tribunal observa que algunas altas cortes nacionales } \\
\text { reconocen daños relativamente similares asociados a la "vida de relación" } \\
\text { u otros conceptos análogos o complementarios. }\end{array}$ \\
\hline
\end{tabular}

Fuente: elaboración propia con base en las decisiones de la CorteIDH.

ii) Reconocimiento público por parte del Estado. Esta categoría de mandatos tiene por objetivo redignificar la vida de las víctimas, haciendo especial énfasis en que se trató de una víctima inocente. En muchos casos, la conculcación del derecho viene acompañada por una serie de justificaciones que pretenden envestir a la víctima con un pasado oscuro o el ejercicio de una actividad ilícita. Es importante que se comunique a la comunidad que el Estado en cuestión es el responsable de los daños producidos para restablecer así el desagravio causado, que puede ir acompañado de una solicitud de perdón por la acción u omisión. Otras medidas de satisfacción que pretenden una reparación a la dignidad de las víctimas son la publicación de la sentencia en un medio de alta circulación, así como el establecimiento de memoriales o centros de memoria. Estos también se encuentran relacionados con la garantía de no repetición.

iii) Garantía de no repetición. Se trata de solicitar al Estado la modificación de ciertas circunstancias que permiten o propician la vulneración de los derechos de sus asociados con el fin de impedir que acontecimientos como los llevados al SIDH no vuelvan a suceder. Para la satisfacción de este rubro se ordenan reformas de tipo legislativo, político y de infraestructura, también se incluyen capacitaciones a servidores públicos con el fin de crear un marco de sensibilización y prevención.

iv) Rehabilitación. Se trata de proveer a la víctima de la atención médica y psicológica necesaria para corregir las secuelas causadas 
por la vulneración a sus derechos o los de sus familiares. Debe garantizársele en forma gratuita, pronta y oportuna el acceso y el goce de la asistencia que requiera según la valoración que se realice en cada caso.

De esta manera, las soluciones amistosas pueden permitir la solución de la controversia, adoptando cualquiera de las medidas de reparación anotadas, que devuelven el conflicto a las partes y permiten una solución rápida y eficaz. Por lo anterior, resulta acertado encuadrar este mecanismo dentro de la baraja de posibilidades con las que cuenta la justicia restaurativa para posicionar a la víctima con miras a buscar su reparación y vincular al agresor y a la comunidad en general con un criterio de cohesión social.

El siDH presenta en la actualidad importantes desafíos para continuar ejerciendo su labor de manera efectiva, así como el derecho penal se ve enfrentado a quiebres y cuestionamientos. En esta estructura regional para la protección de los derechos humanos se entrevén algunas dificultades relacionadas especialmente con la capacidad de respuesta a las múltiples peticiones que recibe, las cuales aumentan con el paso de los años, precisándose que "[e]ste fenómeno ocurre no necesariamente porque en democracia se hayan incrementado las violaciones a los derechos humanos, con respecto a lo que ocurría bajo regímenes autoritarios, sino por la mayor visibilidad y accesibilidad alcanzadas por el sistema interamericano". ${ }^{56}$

Insistimos, el sistema interamericano, al igual que los demás tribunales internacionales de protección de derechos humanos, siguieron o copiaron casi con exactitud los principios del derecho penal clásico y neoclásico sobreponiendo en ellos su estructura y replicando el sistema del derecho castigador como ejemplar y disuasorio de conductas similares. Como es de esperarse cuando se realizan este tipo de trasplantes jurídicos, junto con las bondades y beneficios del derecho penal, se llevaron igualmente los vicios, errores y fallas de este. Aquí radica la importancia de haber examinado la crítica realizada al sistema penal.

Se observa cómo el rol de la CIDH viene a hacer las veces de Fiscal, encargado de investigar los hechos sobre violaciones a los derechos humanos que son puestos en su conocimiento para posteriormente, si lo estima procedente y conveniente, pasar a acusar al Estado frente a la

56 Jesús Orozco, "El proceso de fortalecimiento. Miradas desde el Interior", Revista Aportes DPLF 7, no. 19 (2014), 6. 
CorteIDH con el fin de obtener una condena. Es común escuchar entre quienes se dedican a litigar casos ante el SIDH como acuden a él con el fin de buscar la desaprobación internacional del Estado mediante una sentencia condenatoria y de esta forma cambiar una situación de vulnerabilidad de los derechos humanos que se viene observando de manera estructural al interior del país.

Hasta este momento la víctima no hace aparición alguna en escena. Por el contrario, se ha casado la pelea legislativamente — permitida entre sus apoderados y la CIDH de un lado, y el Estado del otro-, y reaparece la venganza institucionalizada a la que se hacía referencia frente al derecho penal. En este caso, al Estado no se le puede privar de la libertad, debe entonces avergonzársele frente a sus homólogos como prevención especial para que no reincida en la vulneración de los derechos humanos.

Puede verse con claridad que, si la marquesina del proceso penal se ve seriamente debilitada por la incapacidad para resolver los problemas y necesidades para los que fue creada, el futuro del SIDH parece ser muy predecible. Como se señaló, aunque existen sendas diferencias entre uno y otro trámite, la piedra angular de la retribución aparece presente en ambos; este solo hecho hace que la distancia se acorte de forma significativa.

La retribución fue ideada bajo la concepción uno-a-uno, esto es, individuo-a-individuo entendiendo, como se explicó con anterioridad, que el delito es un mal y debe regresarse a su autor un mal proporcional. Pese a que esta dinámica de castigo contiene un gran sentido lógico, el contenido de violencia que lleva implícito genera más violencia y no logra que dejen de cometerse delitos.

Si la represión no es exitosa para los individuos — quienes enfrentan la amenaza del castigo y la privación de la libertad- ¿Por qué tendría que funcionar para un Estado? En efecto, en los sistemas internacionales de justicia en donde se juzga a los países como sujetos del derecho internacional, no puede hablarse de resocialización, pero el señalamiento, reproche y condena de la comunidad mundial no han contribuido a que los vejámenes en contra de la humanidad cesen por parte de estas colectividades, así como tampoco permiten que se los sancione internamente de manera eficaz.

Por ello resulta fundamental que las organizaciones, los Estados y el SIDH se apropien de las soluciones amistosas apostándole a ser una verdadera herramienta de justicia restaurativa. Con ello no solo se contribuye al afianzamiento de la justicia interamericana, sino que, principalmente, 
se logrará que las vidas de miles de personas y comunidades se reparen de forma efectiva.

\section{Conclusiones}

Los esquemas jurídico-penales ante el evidente incumplimiento de los fines para los que fueron creados se han reinventado, haciendo uso de nuevas herramientas que les permitan dar soluciones a los problemas sociales. Se procura el involucramiento de las partes en conflicto, así como de la comunidad que directa o indirectamente también se ve afectada, dentro de un modelo reparador que desafía los postulados básicos de la justicia retributiva.

Esta notoria crisis que se ha querido ejemplificar aquí mediante la dinámica de la penalidad es el denominador común de todas las especialidades de la administración de justicia, que rebasó los límites de operatividad como se ha señalado durante años en los informes temáticos de la Organización de Naciones Unidas y otras similares. Todo proceso nace y se desenvuelve de manera violenta, con enfrentamientos, argumentos desestimadores y con la promesa de un premio solo a uno de quienes participan, que en manera alguna garantiza por sí mismo la solución real de la problemática y menos aún la pacificación de la sociedad en su conjunto.

Bajo esa misma lógica, el SIDH debe aceptar que no está siendo eficiente ante las miles de peticiones que recibe año tras año, es decir, que al igual que el derecho penal, tampoco está dando cumplimiento a los fines de la Convención Americana de Derechos Humanos. En ese sentido, y comoquiera que ya cuenta con un método alterno al tradicional para dar solución a los conflictos que llegan a su conocimiento, debe robustecerlo con miras a que sea una herramienta idónea para dar respuesta a las demandas de justicia.

Como se expuso, la más relevante resulta ser la falta de significación de las soluciones amistosas; por tanto, se pretende aquí dirigirlo hacia una conceptualización como mecanismo de justicia restaurativa, para proponer el uso de los principios, nociones y finalidades aquí expresadas para llenar de contenido el procedimiento interamericano. Con ello también se lograría el acercamiento de las partes y en especial de la víctima, ya que se le daría un tratamiento adecuado y profesional.

Los usuarios del SIDH deben superar las conjeturas según las cuales un procedimiento alternativo no es el llamado a poner fin a una conculcación a los derechos humanos. Debe recordarse que el derecho penal, criticable 
o no, es el encargado de proteger esas prerrogativas fundamentales del individuo al interior de los países y si los diseños de justicia restaurativa pueden ser aplicados en el acaecimiento de un delito que vulnera bienes jurídicos protegidos como la vida, la integridad física, la libertad y otros, que no son otra cosa que auténticos derechos humanos, nada obsta para que se usen en igual medida en los sistemas de protección de estos a nivel internacional.

\section{Referencias}

Bentham, Jeremy. Elpanóptico. Madrid: La piqueta, 1979.

Beristain, Antonio. Nueva criminología desde el derecho penal y la victimología. Valencia: Tirant lo Blanch, 2004.

Braithwaite, John. Restorative justice and responsive regulation. New York: Oxford University Press, 2002.

Braithwaite, John. Crime, Shame and Reintegration. Londres: Cambridge University Press, 1989.

Camargo, Martha. "Víctimas, victimarios y Derechos Humanos". Anuario del Departamento de Derecho de la Universidad Iberoamericana, no. 38 (2008): 231-242.

Cancio, Manuel. "Dogmática y política criminal en una teoría funcional del delito". El sistema funcionalista de derecho penal. Ponencias presentadas en el II Curso Internacional de Derecho Penal, 17-42. Lima: Grijley, 2000.

Carranza, Elías. "Situación penitenciaria en América Latina y el Caribe ¿Qué hacer?”. Anuario de Derechos Humanos, no. 8 (2012): 31-66.

Christie, Nils. "Conflicts as property." The British Journal of Criminology 17, no. 1 (1977): 1-15.

Cid, Jose. La elección del castigo. Barcelona: Bosch, 2009.

Comisión Interamericana de Derechos Humanos. Informe anual de la Comisión Interamericana de Derechos Humanos 2010. Modificado por última vez marzo 7, 2011. Recuperado de http://www.cidh.oas. org/annualrep/2010sp/indice2010.htm

Comisión Interamericana de Derechos Humanos, Informe sobre el impacto del mecanismo de solución amistosa. S. 1.: CIDH, 2013. Recuperado de http://www.oas.org/es/cidh/soluciones_amistosas/docs/InformeSoluciones-Amistosas.pdf

Corte Interamericana de Derechos Humanos, Opinión Consultiva OC-9/87, 6 de octubre de 1987, Serie A no. 9. Recuperado de http://www. corteidh.or.cr/docs/opiniones/seriea_09_esp.pdf 
Cullen, Francis \& Gilbert, Karen. Reaffirming Rehabilition. Cincinnati: Anderson Publishing, 1981.

Díez, José. La racionalidad de las leyes penales. Madrid: Trotta, 2003.

Wyvekens, Anne. "Faget, Jacques. La meditación. Essai de politique pénale, coll. «Trajets», 1997 [compte-rendu]”. Droit et Society, no. 41 (1999): 187-188.

Ferrajoli, Luigi. Derecho y razón. Teoría del garantismo penal. Traducción de Perfecto Ibañez, Alfonso Ruiz, y Juan Bayón. Madrid: Trotta, 2009.

Foucault, Michel. Obrar mal, decir la verdad. Buenos Aires: Siglo xxi Editores, 2014.

Foucault, Michel. La vida de los hombres infames. Madrid: La Piqueta, 1996.

Foucault, Michel. Vigilar y castigar. Nacimiento de la prisión. Buenos Aires: Siglo Xxi Editores, 1976.

Garland, David. Castigo y sociedad moderna. Un estudio de teoría social. Traducción de B. Ruiz. México D.F.: Siglo xxi Editores, 1999.

Hernández, Norberto. El derecho penal de la cárcel. Una mirada al contexto colombiano con base en el giro punitivo y la tendencia al mayor encarcelamiento. Bogotá: Siglo del Hombre Editores, Universidad de los Andes, Universidad EAFIT, 2018.

Hernández, Norberto. "Rol probatorio del apoderado de las víctimas dentro del incidente de reparación integral". Revista Diálogos de Saberes, no. 33 (2010): 261-286.

Hernández, Norberto. "El fracaso de la resocialización en Colombia". Revista de Derecho, no. 49 (2018): 1-41.

Hernández, Norberto. De la privación a la restricción de la libertady otras sanciones penales. ¿Hacia un paradigma restaurativo en la justicia especial para la paz colombiana? (inédito).

Jakobs, Günther. Derecho Penal. Parte General. Fundamentos y Teoría de la Imputación. Traducción de J. Cuellos y J. Serrano. Madrid: Marcial Pons, 1995.

Kemelmajer de Carlucci, Aída. Justicia restaurativa: posible respuesta para el delito cometido por personas menores de edad, Buenos Aires: Rubinzak Culzoni Editores, 2004.

Larrauri, Elena. Introducción a la criminología y al sistema penal. Madrid: Trotta, 2015.

Lastres, Francisco. Estudios Penitenciarios. Madrid: Jiménez Gil Editor, 1887.

Márquez-Algara, María. Mediación penal en México: hacia una justicia restaurativa. México D.F.: Porrúa, 2013. 
Martín, Carlos. Manual sobre perspectiva psicosocial en la investigación de derechos humanos. Bilbao: Instituto Hegoa - UPV/EHU, 2010.

Muñoz, Francisco, “Excurso: Incapacitación: La pena de prisión como simple aseguramiento o inocuización del condenado". En Derecho y Prisiones Hoy, editado por Francisco Javier de León Villalba, 13-24. La Mancha: Ediciones de la Universidad de Castilla.

Neuman, Elías. La mediación penal y la justicia restaurativa. México D.F.: Porrúa, 2005.

Organización de Estados Americanos. Reglamento Comisión Interamericana de Derechos Humanos.

Organización de Estados Americanos y Corte Interamericana de Derechos Humanos, Guía práctica Mecanismo de soluciones amistosas en el sistema de peticiones y casos. http://www.oas.org/es/cidh/soluciones_amistosas/docs/guia-practica-sa-es.pdf

Organización de Naciones Unidas, Consejo Económico y Social. Ad hoc advisory group on African countries emerging from conflicto. Resolución 2002/1. Recuperado de https://www.un.org/ecosoc/sites/www. un.org.ecosoc/files/documents/2002/resolution-2002-1.pdf

Organización de Naciones Unidas, Comité de Derechos Humanos. Informe sobre violaciones de los Derechos Humanos de las personas detenidas en Colombia, 99 período de sesiones, Ginebra, Suiza, Julio de 2010.

Orozco, Jesús. "El proceso de fortalecimiento. Miradas desde el Interior". Revista Aportes DPLF 7, no. 19 (2014): 4-8.

Pavarini, Maximo. “Economía del exceso' y castigos excesivos”. Bulletin de la Société Internationale de Défense Sociale pour une Politique Criminelle Humaniste Cahiers de Defense Sociale, (2004): 230-245.

Rivera, Iñaki. La cuestión carcelaria. Historia, epistemología, derecho y politica penitenciaria. Volumen I. Buenos Aires: Editores del Puerto, 2006.

Roxin, Claus. Derecho penal. Parte general. Tomo I. Traducción y notas de Diego-Manuel Luzón Peña, Miguel Díaz, García Conlledo y Javier de Vicente Remesal. Madrid: Civitas, 1997.

Rusche, Georg. "Labor market and penal sanction: Thoughts on the sociology of criminal justice." En Why punish? How much? A reader on Punishment, edición de Michael Tonry. Nueva York: Oxford University Press, 2011.

Saffón, María \& Uprimny, Rodrigo. "Justicia transicional y justicia restaurativa: tensiones y complementariedades". En ¿justicia transicional sin transición? Verdad, justicia y reparación para Colombia. Bogotá: 
Centro de Estudios de Derecho, Justicia y Sociedad —DeJusticia—, 2006.

Sandoval, Emiro. Penología. Partes general y especial. Bogotá: Ediciones Jurídicas Gustavo Ibáñez, 1998.

Stolzenberg, Lisa, y D'alessio, Stewart. "Three strikes and You're out. The impact of Californian's new mandatory sentencing law on serious crime rates". Crime \& Delinquency 23, no. 4 (1997): 457-469.

Uribe, Juan. "Actitudes de los ciudadanos frente al crimen y al castigo: estudio piloto en la Universidad EAFIT, Medellín". Revista Nuevo Foro Penal 9, no. 81 (2013): 232-300.

Varona, Daniel. "Ciudadanos y actitudes punitivas: Un estudio piloto de población universitaria española". Revista Española de Investigación Criminológica, no. 6 (2008): 1-38.

Varona, Daniel. “¿Somos los españoles punitivos? Actitudes punitivas y reforma penal en España”. Revista Indret, no. 1 (2009): 1-31.

Von hirsch, Andrew, Bottoms, Anthony E., Burney. Elizabeth, \& Wikstrom, P-O. Criminal deterrence and sentence severity. Oxford: Hart Publishing, 1999.

Wasik, Martin \& Von hirsch, Andrew. "Non-custodialpenalties and the principles of desert", The Criminal Law Review, (1998): 555-572.

Zaffaroni, Eugenio, Alagia, Alejandro, \& Slokar, Alejandro. Derecho Penal. Parte general. Buenos Aires: Ediar, 2000. 